\title{
ANÁLISE DA PERMEABILIDADE E DOS MÉTODOS DE INSTALAÇÃO DE PAVIMENTOS PERMEÁVEIS CONTIDOS EM ARTIGOS CIENTÍFICOS E EM CATÁLOGOS TÉCNICOS
}

\author{
Geovana Geloni Parra
}

\author{
Bernardo Arantes do Nascimento Teixeira
}

\begin{abstract}
RESUMO
A alta impermeabilização do solo e o aumento das enchentes, bem como a má qualidade da água e a necessidade de preservação dos recursos hídricos, impulsionou nos últimos anos a utilização e o desenvolvimento de novas tecnologias relacionadas a drenagem urbana sustentável. Dessa maneira os pavimentos permeáveis estão sendo muito utilizados para minimizar os impactos causados pela impermeabilização do solo. A maior parte dos locais em que está implantado são em áreas destinadas ao tráfego leve de veículos ou estacionamentos, porém surge aos poucos, locais em que este tipo de pavimento vem sendo executado em calçadas, praças e parques. O objetivo é pontuar as divergências e convergências entre pesquisadores e fornecedores de pavimentos alternativos, e a aplicabilidade de cada pavimento. Foram realizados comparativos entre taxas de permeabilidade, estudos de trabalhos científicos, identificação dos pavimentos hidrologicamente funcionais, e busca por fornecedores e seus catálogos técnicos.
\end{abstract}

Palavras-Chave: pavimentos permeáveis, taxa de permeabilidade, instalação de pavimentos permeáveis.

\section{ANALYSIS OF PERMEABILITY AND METHODS OF INSTALLATION OF PAVEMENTS PERMEABLE IN SCIENTIFIC ARTICLES AND IN TECHNICAL CATALOGUES}

\begin{abstract}
The high impermeabilization of soil and the increase of the floods, well as the bad quality of water and the necessity of hydric resources preservation, it has boosted in the last years an application and the development of new Technologies related a sustainable urban drainage. This manner the permeable pavements are very applied to minimize the impacts caused by soil impermeabilization. The mostly of the places that is implanted are in areas destinated a cars low traffic or parkings, however, arise gradually, places that this type of pavement it being executed in sidewalks, squares, and parks. The
\end{abstract}


Revista Nacional de

Gerenciamento de Cidades

goal is punctuate the divergence and convergence between permeability rates, study of scientific Works, identification of hydrologically functional pavements, and search of suppliers and technical catalogues.

Key words: permeable pavements, permeability rate, installation permeable pavements.

\section{ANÁLISIS DE LA PERMEABILIDAD Y LOS MÉTODOS DE INSTALACIÓN DE LOS PAVIMENTOS PERMEABLES EN ARTÍCULOS CIENTÍFICOS Y EN LOS CATÁLOGOS TÉCNICOS}

\section{RESUMEN}

El sellado de alta del suelo y el aumento de las inundaciones y la mala calidad del agua y la necesidad de preservar los recursos hídricos, ten impulsado en los últimos años el uso y desarrollo de las nuevas tecnologías relacionadas con el drenaje urbano sostenible. De esta manera los pavimentos permeables están siendo ampliamente utilizados para minimizar los impactos causados por el sellado del suelo. La mayoría de los lugares que se implementan son en áreas destinadas a la luz de tránsito o estacionamiento de vehículos lotes, pero emerge gradualmente, lugares en los que este tipo de pavimento se ejecutan en aceras, plazas y parques. El objetivo es anotar las divergencias y convergencias entre los investigadores y proveedores de pavimentos alternativos y la aplicabilidad de cada pavimento. Se realizaron comparaciones entre las tasas de permeabilidad de los estudios de los trabajos científicos, la identificación de pavimentos hidrológicamente funcionales, y la búsqueda de proveedores y sus catálogos técnicos.

PALABRAS-CLAVE: pavimentos permeables, tasa de permeabilidad, instalación de pavimentos permeables.

\section{INTRODUÇÃO}

A busca por tecnologias mais sustentáveis na construção do ambiente urbano tem levado a utilização de técnicas que possibilitam um menor desgaste ao meio ambiente. A alta impermeabilização do solo e o aumento das enchentes, bem como a má qualidade da água e a necessidade de preservação dos recursos hídricos, impulsionou nos últimos anos a utilização e o desenvolvimento de novas tecnologias relacionadas a drenagem urbana sustentável.

Este cenário o qual o Brasil se encontra, tem despertado o interesse de pesquisadores e empresários. O interesse por parte dos pesquisadores ocorre visando a importância de minimizar as áreas impermeabilizadas, preservar as 
condições naturais do espaço. Já o interesse dos empresários vem a partir desta nova linha de ação e mudança no comportamento das pessoas em relação a consciência ecológica. Dessa maneira é importante avaliar como estão ocorrendo estas transformações.

Os pavimentos permeáveis estão sendo muito utilizados como maneira de minimizar os impactos causados pela impermeabilização do solo. A maior parte dos locais em que está implantado são em áreas destinadas ao tráfego leve de veículos ou estacionamentos. Porém surge aos poucos, locais em que este tipo de pavimento vem sendo executado em calçadas, praças e parques.

A execução dos pavimentos permeáveis muitas vezes não é feita de maneira correta, vimos que muitos lugares executam um contra-piso antes de seu assentamento ou compactam o solo de maneira a deixa-lo praticamente impermeável, excluindo assim o real funcionamento para qual o piso foi fabricado. Por isso a necessidade de verificar quais são as diretrizes técnicas de implantação oferecidas em catálogos técnicos como também em pesquisas acadêmicas.

\subsection{Objetivo e Metodologia}

Neste trabalho o objetivo é pontuar as divergências e convergências entre pesquisadores e fornecedores de pavimentos alternativos, e a aplicabilidade de cada pavimento.

Para o desenvolvimento deste trabalho o método empregado consistiu na realização das seguintes atividades:

- Comparativos entre as taxas de infiltração e deslocamento das águas pluviais superficiais em situação convencional, e em situação de aplicação dos pavimentos hidrologicamente funcionais.

- Estudo de trabalhos científicos que apresentem ensaios com diferentes tipos de superfícies em eventos de chuva e que mostram a eficiência dos tipos de pavimentos em relação a infiltração. 


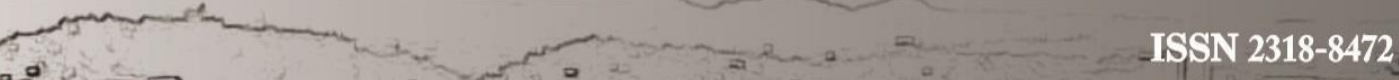

\section{Revista Nacional de}

- Identificação dos diferentes tipos de pavimentos a partir de trabalhos acadêmicos e fornecedores, através de consultas a bibliografia, sites e catálogos técnicos.

\section{DESENVOLVIMENTO}

\subsection{Abordagem em artigos científicos}

Pesquisas realizadas vem encontrando resultados referentes a funcionalidade hidrológica da pavimentação, como taxas de escoamento entre diferentes tipos de pavimentos. Muitos desses estudos são realizados em modelos experimentais com chuvas simuladas e não em meios naturais e escala real.

Um estudo realizado por Moura (2005), teve como objetivo comparar e quantificar a eficiência de superfícies permeáveis. O trabalho apresenta 0 comportamento de 4 tipos de superfícies permeáveis: grama, chão batido, blocos maciços e blocos vazados. Foi utilizado para experiência uma área de $1 \mathrm{~m}^{2}$ para cada tipo de superfície, onde foram feitas simulações de chuva para avaliar o comportamento do escoamento e da infiltração em cada uma delas, como apresentado na Tabela 1:

Tabela 1: Tabela da Média dos dados da taxa média de infiltração encontrados no estudo experimental realizado por Moura (2005)

\begin{tabular}{c|c|c|c|c|c|c}
$\begin{array}{c}\text { Tipo de } \\
\text { superfície }\end{array}$ & $\begin{array}{c}\text { Solo } \\
\text { gramado }\end{array}$ & $\begin{array}{c}\text { Chão } \\
\text { Batido }\end{array}$ & $\begin{array}{c}\text { Bloco } \\
\text { Maciço sem } \\
\text { compacta- } \\
\text { ção }\end{array}$ & $\begin{array}{c}\text { Bloco } \\
\text { Maciço com } \\
\text { compacta- } \\
\text { ção }\end{array}$ & $\begin{array}{c}\text { Bloco } \\
\text { Vazado com } \\
\text { compacta- } \\
\text { ção }\end{array}$ & $\begin{array}{c}\text { Bloco } \\
\text { Vazado } \\
\text { sem } \\
\text { compacta- } \\
\text { ção }\end{array}$ \\
\hline $\begin{array}{c}\text { Média da } \\
\text { Taxa de } \\
\text { Infiltração }\end{array}$ & 103,5 & 51 & 59 & 24,5 & 93 & 53 \\
\hline $\begin{array}{c}\text { Média do } \\
\text { Coeficiente de } \\
\text { escoamen-to }\end{array}$ & 0,21 & 0,57 & 0,63 & 0,72 & 0,2 & 0,51 \\
\hline
\end{tabular}

Fonte: MOURA, 2005 
Revista Nacional de

Gerenciamento de Cidades

Já a pesquisa realizada por Bruno et al.(2013) também avalia experimentalmente as seguintes estruturas: solo gramado, solo exposto, blocos de concreto maciço, blocos de concreto vazado e piso de concreto convencional, com simulação de chuva. A área está localizada no campus da Universidade Federal do Mato Grosso e o tipo de solo é argiloso. Cada parcela experimental tem $0,70 \mathrm{~m}^{2}$ de área e foram isoladas por um quadro metálico. O estudo avalia o escoamento de água da chuva em duas situações de intensidade de precipitação, $79 \mathrm{~mm} / \mathrm{h}$ e $121 \mathrm{~mm} / \mathrm{h}$, com três ensaios em cada uma das cinco superfícies, como pode ser visto na Tabela 2:

Tabela 2: Taxas de infiltração média encontradas por Bruno et al.(2013)

\begin{tabular}{c|c|c|c|c|c} 
Tipo de superfície & $\begin{array}{c}\text { Solo } \\
\text { gramado }\end{array}$ & $\begin{array}{c}\text { Solo } \\
\text { exposto }\end{array}$ & $\begin{array}{c}\text { Bloco de } \\
\text { concreto } \\
\text { maciço }\end{array}$ & $\begin{array}{c}\text { Bloco de } \\
\text { concreto } \\
\text { vazado }\end{array}$ & $\begin{array}{c}\text { Concreto } \\
\text { convencional }\end{array}$ \\
\hline $\begin{array}{c}\text { Intensidade de } \\
\text { Precipitação } \\
79 \mathrm{~mm} / \mathrm{h}\end{array}$ & $\begin{array}{c}\text { Infiltração } \\
\text { total }\end{array}$ & 29,15 & 48,2 & 78,07 & 3,11 \\
\hline $\begin{array}{c}\text { Intensidade de } \\
\text { Precipitação } \\
121 \mathrm{~mm} / \mathrm{h}\end{array}$ & 96,3 & 42,85 & 48,71 & 84 & 6,01 \\
\hline
\end{tabular}

Fonte: BRUNO et al, 2013

Com este resultado é clara a importância dos impactos causados pela retirada de vegetação do solo, em relação ao escoamento superficial gerado durante os eventos de chuva. Sendo assim se faz necessário a busca de alternativas de revestimentos do solo que possam minimizar os impactos causados ao meio natural.

A manutenção dos pisos permeáveis é muito importante visto que quando a estrutura colmata, ela para de infiltrar, aumentando a taxa de escoamento superficial. A execução do pavimento também contribui para esta colmatação, se a instalação ocorrer de maneira inadequada, a estrutura não funcionará de maneira correta. 
Revista Nacional de

Barbosa e Moura(2014), analisaram a vida útil da permeabilidade dos pavimentos permeáveis para 15 anos, pois estas estruturas estão sujeitas a colmatação ao longo do tempo de uso. Os ensaios foram realizados com base na norma ASTM C1701, com teste em pavimentos permeáveis de $40 \%$ de área livre, em 13 locais da cidade de Belo Horizonte/MG, sendo estacionamentos e postos de combustíveis. Os resultados encontrados mostram que quanto mais novo o pavimento maior a taxa de infiltração e que com o passar dos anos esta taxa de infiltração se estabiliza, tornando-se constante.

Segundo a $A B C P(2011)$, o ensaio para determinação do coeficiente de infiltração em piso permeável deve ser feito segundo a ASTM C1701, um anel de infiltração é temporariamente selado na superfície do pavimento permeável, depois de pré-molhar o local de teste, uma quantidade de massa de água é adicionada no anel e é registrado o tempo para infiltrar água no pavimento. Para este ensaio são necessários cilindro de infiltração, balança, recipiente, cronometro, massa de calafetar e água. São necessários três locais para testes em espaços de até $2500 \mathrm{~m}^{2}$, e um teste a mais para cada $1000 \mathrm{~m}^{2}$, deixar uma distância de pelo menos 1 m livre entre os locais de teste, e o teste não deve ser executado em menos de 24 horas da última precipitação.

Os sedimentos que se acumulam no pavimento tendem a diminuir a infiltração ao longo dos anos, segundo a $\operatorname{ABCP}(2011)$ considera-se que em 10 anos o pavimento permeável tenha uma redução de $90 \%$ da sua capacidade de infiltração. Após esse período o rejunte pode ser trocado para que o pavimento volte a ter sua capacidade de infiltração. A associação também sugere que anualmente seja efetuada uma limpeza retirando os sedimentos acumulados, como também a retirada da vegetação que cresce entre as juntas.

De acordo com a ABCP (2011), as etapas de execução da pavimentação permeável podem ser divididas em dois tipos: pavimento intertravado permeável e pavimento de concreto permeável. A execução da pavimentação de piso intertravado permeável é dividida em 11 etapas:1 Etapa: limpeza do terreno e 
Revista Nacional de

abertura da caixa de pavimentação; 2a Etapa: terraplanagem; 3ำ Etapa: compactação do subleito, espalhamento e compactação do solo de reforço e nivelamento quando necessário; 4 a Etapa: instalação da rede de drenagem; $5^{\text {a }}$ Etapa: assentamento da manta geotêxtil; 6를 Etapa: Espalhamento das camadas de britas; $7^{\mathrm{a}}$ Etapa: Compactação das camadas de brita; 8를 Etapa: Execução das guias e sarjetas; 9a Etapa: Assentamento dos blocos de concreto; 10ª Etapa: Rejunte dos blocos com pedriscos; $11^{\underline{a}}$ Etapa: Obra finalizada.

A ABCP(2011) também cita as etapas de execução de pavimentação dos pavimentos de concreto permeável, que difere da pavimentação permeável em cinco etapas finais:

9a Etapa: Espalhamento do concreto permeável de maneira rápida e continua, o espalhamento deve ser feito sob a base/subleito úmidos para evitar perda de água do concreto;10를 Etapa: Nivelamento utilizando régua vibratória ou manualmente com régua de alumínio, não vibrar por muito tempo pois pode entupir os vazios do concreto, nivelar de 15 a $20 \mathrm{~mm}$ acima das guias para permitir a posterior compactação;1 1 $1^{\text {a }}$ Etapa: Consolidação do concreto através da compactação utilizando rolo compactador, esta etapa deve ser feita rapidamente;12 $2^{\mathrm{a}}$ Etapa: Execução de juntas de dilatação a cada $6 \mathrm{~m}$ com profundidade de $1 / 4$ da espessura da placa do concreto logo após a consolidação;13a Etapa: Cura e proteção do concreto fresco, proteção com manta plástica, a cura deve ser iniciada logo após a execução da junta.

\subsection{Estudo de Catálogos Técnicos de Fornecedores de Pavimentos Hidrologicamente Funcionais}

A busca de catálogos técnicos de fornecedores de pavimentos hidrologicamente funcionais ocorreu de maneira a selecionar os tipos de pavimentos encontrados nas pesquisas acadêmicas e conhecer também os dados encontrados pelos fabricantes. 


\section{Revista Nacional de}

Assim, a partir da revisão bibliográfica realizada em trabalhos acadêmicos foram identificados os pavimentos porosos ou drenantes, intertravados, e pisos gramas.

Os fabricantes foram encontrados em revistas técnicas dedicadas ao meio comercial, e a partir delas, a pesquisa prosseguiu direto pelo meio eletrônico através da internet. A seleção dos fabricantes a serem estudados neste trabalho se deve pelo maior número de informações encontradas, como catálogos técnicos, laudos de permeabilidade, resistência e refletância solar. Foram encontrados no total vinte e três fabricantes de pisos intertravados e pisos gramas com o selo de qualidade ABCP (Associação Brasileira de Cimento Portland), e sete fabricantes de pisos drentantes ou porosos. Desse foram escolhidos 4 fabricantes para estudo.

Três tabelas (Tabelas 3, 4 e 5) foram elaboradas com o propósito de caracterizar os pavimentos encontrados, onde estão caracterizados por variáveis de interesse: espessura, permeabilidade, absorção de água, resistência, dimensões, tipos de tráfego, limpeza, e material. Os catálogos técnicos pesquisados também trazem informações referentes a instalação e transporte. São utilizados legendas NA (não se aplica) e NE (não especificado).

Tabela 3: Tabela comparativa de tipos de pavimentos porosos Fornecedor 1

\begin{tabular}{|c|c|c|c|c|c|c|c|}
\hline Tipo de pavimentos & \multicolumn{4}{|c|}{ Pavimento poroso } & \multicolumn{3}{|c|}{ Concreto poroso } \\
\hline Espessura $(\mathrm{cm})$ & 6 & 6 & 6 & 10 & 8 & 8 & 8 \\
\hline Permeabilidade $(\mathrm{mm} / \mathrm{h})$ & 8500 & 8679 & 6142 & 8680 & 6357 & 13821 & 5107 \\
\hline Absorção de água & \multicolumn{7}{|c|}{ NA } \\
\hline Resistência & \multicolumn{7}{|c|}{$25 \mathrm{Mpa}$} \\
\hline Dimensões(cm) & $20 \times 10 \times 6$ & $20 \times 20 \times 6$ & $40 \times 40 \times 6$ & $20 \times 10 \times 10$ & $20 \times 10 \times 8$ & $20 \times 20 \times 8$ & $40 \times 40 \times 8$ \\
\hline Tráfego & \multicolumn{3}{|c|}{ Pedestres e bicicletas } & NE & \multicolumn{3}{|c|}{$\begin{array}{l}\text { Pedestres/ bicicletas/acesso } \\
\text { de veículos/motocicletas }\end{array}$} \\
\hline Limpeza & \multicolumn{7}{|c|}{$\begin{array}{l}\text { Varrer com cerdas duras, se necessário aplicar sabão neutro, mangueira } \\
\text { de alta pressão, realinhar a areia das juntas perdidas durante a limpeza }\end{array}$} \\
\hline Composição & \multicolumn{7}{|c|}{ Concreto poroso } \\
\hline
\end{tabular}

Fonte: Fornecedor 1 


\section{Revista Nacional de}

Gerenciamento de Cidades

Tabela 4: Tabela comparativa de tipos de pavimentos porosos fornecedores diversos

\begin{tabular}{c|c|c|c} 
Tipo de pavimentos & \multicolumn{3}{|c}{ Pavimento poroso } \\
\hline Fornecedor & $\mathbf{2}$ & $\mathbf{3}$ & $\mathbf{4}$ \\
\hline Espessura $(\mathrm{cm})$ & $6 / 8 / 10$ & 5 & 4,3 \\
\hline Permeabilidade $(\mathrm{mm} / \mathrm{h})$ & 15786 & 23400 & 9756 \\
\hline Absorção de água & & $\mathrm{NA}$ & $1,5 \mathrm{MPa}$ \\
\hline Resistência & $2,91 \mathrm{MPa}$ & $\mathrm{NE}$ & $50 \times 50$ \\
\hline Dimensões(cm) & $50 \times 50 \times 8$ & $60 \times 60 \times 5$ & $\begin{array}{c}\text { Pedestres e } \\
\text { Estacionamentos }\end{array}$ \\
\hline Tráfego & $\begin{array}{c}\text { Pedestres/Veículos de } \\
\text { passeio/caminhões leves }\end{array}$ & $\begin{array}{c}\text { Pedestres e } \\
\text { Estacionamentos }\end{array}$ \\
\hline Limpeza & $\begin{array}{c}\text { Aspirar e Água } \\
\text { pressurizada }\end{array}$ & $\begin{array}{c}\text { Detergente alcalino e } \\
\text { água pressurizada }\end{array}$ & $\begin{array}{c}\text { Água pressurizada } \\
\text { Composição }\end{array}$ \\
\hline
\end{tabular}

Fonte: Fornecedores diversos

Tabela 5: Tabela comparativa de tipos de pavimentos tipo intertravados e piso grama fornecedor 1

\begin{tabular}{|c|c|c|c|}
\hline \multirow{2}{*}{$\begin{array}{c}\text { Tipo de pavimentos } \\
\text { Espessura }(\mathrm{cm})\end{array}$} & \multicolumn{2}{|c|}{ Piso intertravado de concreto } & \multirow{2}{*}{$\begin{array}{c}\text { Piso grama de concreto } \\
1\end{array}$} \\
\hline & 8 & 1 & \\
\hline Permeabilidade(mm/h) & \multicolumn{2}{|c|}{ NA } & $\mathrm{NE}$ \\
\hline Absorção de água & $5 \%$ & $4 \%$ & NE \\
\hline Resistência & $35 \mathrm{Mpa}$ & 50Mpa & $35 \mathrm{MPa}$ \\
\hline Dimensões(cm) & $23 \times 11 \times 8$ & $23 \times 11 \times 8$ & $29 \times 43 \times 6 / 29 \times 43 \times 8$ \\
\hline Tráfego & Pedestres & $\begin{array}{l}\text { Veículos } \\
\text { especiais }\end{array}$ & Acesso de veículos \\
\hline Limpeza & \multicolumn{2}{|c|}{$\begin{array}{l}\text { Varrer com cerdas duras, } \\
\text { aplicar sabão neutro, água } \\
\text { pressurizada, realinhar as } \\
\text { areias das juntas perdidas } \\
\text { durante a limpeza. }\end{array}$} & $\begin{array}{c}\text { Varrer com cerdas duras, aplicar sabão } \\
\text { neutro, água pressurizada, realinhar as } \\
\text { areias das juntas perdidas durante a } \\
\text { limpeza. Raspar e retirar o material } \\
\text { acumulado em camadas grossas. Aplicar } \\
\text { um herbicida especial para limo } \\
\text { escovando-se e seguindo as instruções do } \\
\text { fabricante. }\end{array}$ \\
\hline Composição & \multicolumn{3}{|r|}{ Concreto } \\
\hline
\end{tabular}

Fonte: Fornecedor 1 


\section{Revista Nacional de}

Gerenciamento de Cidades

As tabelas permitem verificar que existem diferenças entre as taxas de permeabilidade encontradas entre pavimentos do mesmo fornecedor, como também diferentes espessuras das peças, as quais caracterizam o uso permitido por cada uma.

As peças que apresentam espessuras de $6 \mathrm{~cm}$ são mais adequadas para pedestres e bicicletas, enquanto que as de $8 \mathrm{~cm}$ permitem o acesso de veículos de passeio, e as peças de $10 \mathrm{~cm}$ permitem o tráfego de caminhões leves.

Os pisos porosos ou drenantes estabelecem taxas de permeabilidade, enquanto os pisos intertravados e pisos gramas taxas de porcentagem de absorção de água. Entre os fornecedores a maior taxa de permeabilidade encontrada foi a do fornecedor 3 , referente ao piso drenante sendo de $23400 \mathrm{~mm} / \mathrm{hora}$. A menor taxa de permeabilidade foi a do piso drenante do fornecedor 1 modelo de dimensão $40 \times 40 \times 6 \mathrm{~cm}$. Os ensaios de permeabilidade realizados pelo fornecedor 1 para os pisos porosos ou drenantes foram realizados pela $A B C P$ em abril de 2012. $O$ método utilizado foi referenciado pelo método da American Concrete Institute - ACl 522R-06 Pervious Concrete, que utiliza um permeâmetro de carga variável.

Esta metodologia consiste segundo laudo realizado pela $\operatorname{ABCP}(2012)$ na adição de água ao tubo de entrada de maneira a saturar a amostra de concreto poroso até que o nível se iguale entre o topo da amostra e o topo do tubo de dreno. A seguir a válvula é fechada e o tubo graduado de entrada é preenchido com uma coluna d'água de $290 \mathrm{~mm}(\mathrm{~h})$. Após esta etapa a válvula é aberta e registra-se o intervalo de tempo que a coluna d'água demora para abaixar de $290 \mathrm{~mm}\left(h_{i}\right)$ até $70 \mathrm{~mm}\left(\mathrm{~h}_{\mathrm{f}}\right)$. Este procedimento é repetido três vezes para cada corpo de prova e considera-se o tempo médio.

Para este mesmo tipo de pavimento, a fabricante 2, apresenta um laudo emitido pela Falcão Bauer(2007), a metodologia apresentada inicialmente determina a massa do corpo de prova (M1), e em seguida a placa drenante é disposta sobre um recipiente metálico (R1), a fim de permitir o escoamento da água sobre a face do corpo de prova, para outro recipiente metálico (R2). Em seguida acrescenta sobre o 


\section{Revista Nacional de}

corpo de prova um volume de água, onde é verificado o volume escoado pelo piso drenante. Após este período foi verificado o volume de água drenada em R1; determinada a sua massa (M2) e também o volume de água escoada pela superfície.

O fornecedor 3 em seu catalogo técnico não informou como foram realizados os ensaios de permeabilidade, em contato por e-mail diretamente com a empresa, a informação obtida é que estão trabalhando em conjunto com as normas apresentadas pela $\mathrm{ABCP}$.

O fornecedor 4, não informa em seu catalogo técnico a metodologia utilizada para a conhecimento da taxa de permeabilidade.

A indicação de manutenção em geral é a mesma independente do fabricante, é aconselhado varrer o espaço, lavar com sabão neutro quando necessário, e lavadora de alta pressão. $O$ fornecedor 2 sugere a aspiração da sujeira encontrada nos pisos.

As normas para instalação dos pisos apresentam algumas variantes de acordo com cada fabricante. A instalação do pavimento permeável drenante em concreto poroso segundo o fornecedor 1 sugere dois tipos de instalação. A primeira forma de implantação indica uma camada de $6 \mathrm{~cm}$ de pedrisco lavado compactado e, $2 \mathrm{~cm}$ de areia grossa, e em seguida o assentamento do piso permeável com uma camada de brita ํo 1 ou ํㅡㄴ isenta de pó e compactada, com índice de vazios de $30 \%$, a altura desta camada deve ser de três vezes o índice pluviométrico médio do local, em seguida uma camada de $6 \mathrm{~cm}$ de pedrisco lavado compactado, em seguida uma camada de $2 \mathrm{~cm}$ de areia grossa, e por último o assentamento do piso permeável.

O fornecedor 2 em seu catalogo técnico explica que a superfície deve ser plana, com solo sem excesso de argila, areia ou umidade. A área deve ser escavada, deixando um mínimo de $10 \mathrm{~cm}$ de profundidade e inclinação entre $1 \% \mathrm{e}$ $5 \%$, na direção do escoamento da água. Em seguida deve ser realizado o travamento do perímetro que receberá o piso drenante, essa delimitação impede a 
Revista Nacional de

Gerenciamento de Cidades

movimentação das placas durante e após o uso. Após esta etapa deve-se aplicar uma camada de 4 a $6 \mathrm{~cm}$ de brita ำ2 e regularizar o nivelamento do solo, caso haja a necessidade de tubulação drenante auxiliar deve ser realizada nesta etapa e se utilizada é necessário a colocação de manta geotêxtil. Outra camada com 4 a $6 \mathrm{~cm}$ de pedriscos deve ser aplicada sobre a brita, e em seguida a compactação. Finalmente chega-se a etapa de colocação das placas que devem ser preenchidas com areia como rejunte, em seguida o rejunte drenante da própria fabricante. Um martelo de borracha deve ser utilizado para o pré-acerto das placas, e após isto para o nivelamento utiliza-se uma placa vibratória sobre chapa de madeirite.

O fornecedor 3 instrui o assentamento do seu piso permeável drenante com a primeira etapa sendo a contenção do espaço, em seguida a compactação do solo, colocação de manta geotêxtil, execução de camada base com agregados miúdos de dimensão aproximada de 9,5mm, aplicação de pedriscos para nivelamento do berço das placas de piso, e em seguida assentar as peças com juntas secas ou juntas de $3 \mathrm{~mm}$, o rejuntamento pode ser feito com agregados mais finos do que os utilizados na camada de assentamento, e a fabricante ainda alerta para a importância da não utilização de areia grossa ou pó de pedra devido ao baixo coeficiente de permeabilidade destes materiais

O fornecedor 4 descreve as instruções de assentamento em sete etapas: limpar e compactar o solo com inclinação de até $5 \%$; aplicação de uma camada de 4 a $6 \mathrm{~cm}$ de brita $\mathrm{n}^{\circ} 1$, nivelar e compactar; aplicação de camada de pedriscos de 4 a $6 \mathrm{~cm}$, nivelar e compactar; aplicar uma camada de $3 \mathrm{~cm}$ de pó de pedra, limpo e seco, realizando o nivelamento com um sarrafo; instalar as placas de piso com juntas de $5 \mathrm{~mm}$; confinamento da área de instalação com guias nas laterais; preenchimento das juntas com areia grossa ou granilha, devendo este passo ser revisado após 10 dias da instalação ou após uma chuva intensa.

O fornecedor 1 de pisos intertravados não fornece informações sobre a instalação deste pavimentos, porém apresenta esquemas ilustrativos para a instalação do piso grama de sua fabricação. São duas formas, uma com grama e 


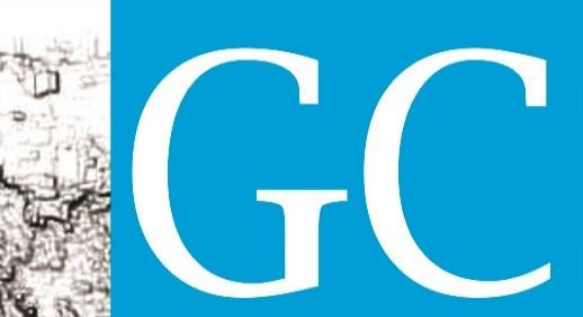

Revista Nacional de

Gerenciamento de Cidades

outra com pedriscos. $O$ assentamento com grama (Figura 1)exige apenas a execução de uma camada com $2 \mathrm{~cm}$ de areia grossa, já o assentamento com pedriscos (Figura 2) exige uma camada de $6 \mathrm{~cm}$ de pedrisco compactado e a camada de $2 \mathrm{~cm}$ de areia grossa, e em seguida em ambos os modos de assentamento a colocação das peças de piso grama.

Figura 1: Figura ilustrativa do assentamento dos pisos grama com grama Fornecedor 1

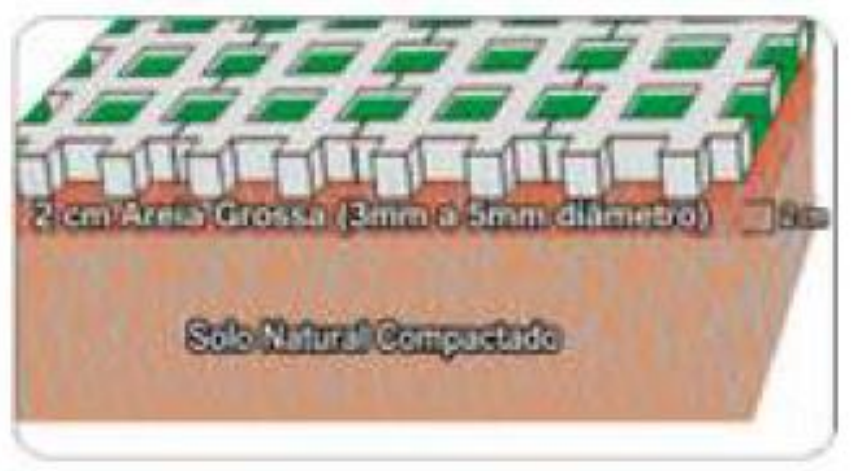

\section{Fonte: Fornecedor 1}

Figura 2: Figura ilustrativa do assentamento dos pisos grama com grama Fornecedor 1

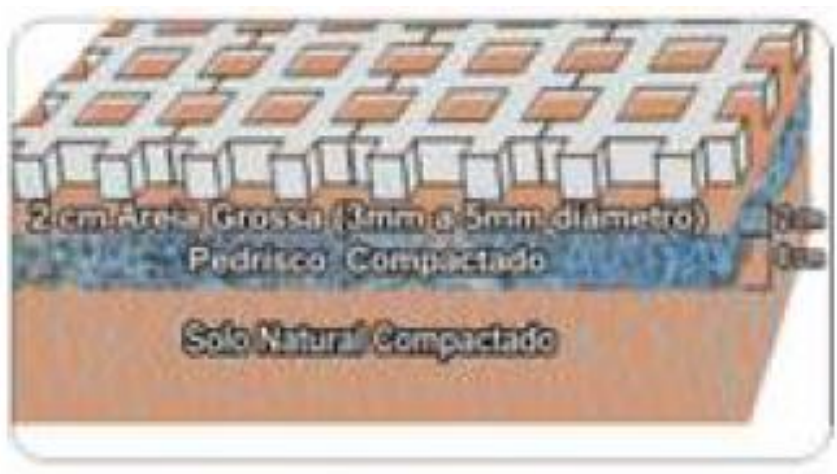

Fonte: Fornecedor 1 


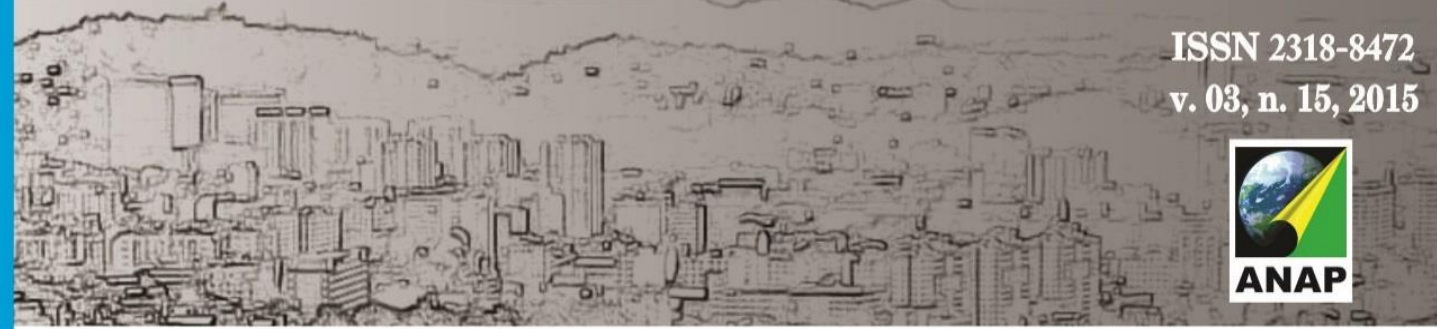

Revista Nacional de

Gerenciamento de Cidades

\section{RESULTADOS}

Estes trabalhos mostram que a grama possui a maior taxa de infiltração e o menor coeficiente de escoamento superficial, enquanto que o bloco de concreto convencional o maior coeficiente de escoamento.

O concreto poroso apresenta índices muito próximos ao do solo gramado, e o solo exposto índices comparados ao bloco de concreto convencional.

A ABCP sugere um método de ensaio para determinação do coeficiente de infiltração baseado na norma ASTM C1701, e que a instalação dos pavimentos permeáveis devem prever a compactação do solo para nivelamento das peças, bem como a instalação da rede de drenagem antes da colocação da manta geotêxtil.

Os fornecedores utilizam diferentes formas de ensaio como testes com o permeâmetro, que tem como referência o método da $\mathrm{ACl}$ 522R-06 Pervious Concrete, utilizam o método de diferença de volume aplicado em um corpo de prova e o volume escoado; e também o método da $A B C P$.

A manutenção é unânime entre os fabricantes que deve ser realizada basicamente com a varrição e lavadora de alta pressão. Um dos estudos científicos relatou a importância da manutenção para garantir o bom funcionamento dos pisos.

Quanto a forma de instalação existem algumas divergências entre os fornecedores, dentre elas, a utilização do índice pluviométrico do local deve ser levado em conta para o dimensionamento das camadas de pedriscos, o solo não deve ser argiloso, contenção da área de implantação como primeiro passo, enquanto outro fornecedor afirma que deve vir como penúltimo passo. Todos os fornecedores incluem a compactação do solo em suas etapas iniciais, exceto um dos fabricantes que realiza a compactação somente após a colocação dos pedriscos. 


\section{CONCLUSÃO}

O assentamento dos pisos permeáveis deve procurar atender os padrões estabelecidos pelo fabricante, porém atentar-se para a compactação do solo e para o confinamento das placas, se o solo for muito compactado o piso permeável para de exercer sua função, como foi possível observar com os valores encontrados nos trabalhos científicos.

Cada fornecedor realiza o teste de permeabilidade de uma maneira, apenas um realiza o teste segundo a ABCP. A Norma Brasileira para pavimentos permeáveis ainda está em fase de elaboração, enquanto isso é possível observar que cada fornecedor utiliza a metodologia que mais lhe convém. A partir da normatização será possível equiparar os índices de permeabilidade e de instalação com mais precisão.

Porém mesmo com essas divergências de métodos de análise de permeabilidade, a conclusão é de que é necessário reduzir a impermeabilização do solo, procurando manter situações de pré-ocupação como solos gramados ou vegetação local na maior área possível. Quando necessário a pavimentação para melhor acessibilidade dos pedestres deve ser de pisos de concreto drenante ou porosos, pois como verificado nos trabalhos científicos é considerado o de menor escoamento superficial, e nos catálogos técnicos os de maior permeabilidade.

Sendo assim, diretrizes para a utilização destes tipos de piso seriam mais adequadas para o planejamento das cidades como meio de melhorar a vida das pessoas e de outros seres vivos que habitam o planeta. Estes pisos podem ajudar a reduzir a ocorrência de enchentes e quando realizadas as manutenções se apresentam como bom caminho para pedestres. 


\section{REFERÊNCIAS BIBLIOGRÁFICAS}

ACQUADRENO PISOS DRENANTES: Disponível em < www.acquadreno.com.br > Acesso em 27/10/2014

BARBOSA, R. S.; MOURA, P. M. (2014). Análise da Permeabilidade de Pavimento Intertravado Vazado. In Anais do X Encontro Nacional de Águas Urbanas, São Paulo, Set. 2014

BRASTON PISOS PERSONALIZADOS: Disponível em: <www.braston.com.br> Acesso em: 15/02/2015;

BRUNO, L. O.; AMORIM, R. S. S.; SILVEIRA A. Estudo da redução do escoamento superficial direto em superfícies permeáveis. RBRH - Revista Brasileira de Recursos Hídricos, Vol. 18, n², 237-247p. abr/jun, 2013.

CASTELLATO PISOS E REVESTIMENTOS: Disponível em < www.castellato.com.br > Acesso em 27/10/2014

COUPE, S.J., et al. New developments in permeable pavement design to improve water quantity na quality. Novatech, 2013.

JUNIOR, L. L. C.; BARBASSA, A. P. Parâmetros de projeto de microrreservatório, de pavimentos permeáveis e de previsão de enchentes urbanas. Engenharia Sanitária e Ambiental, Vol. 11, no 1, 4654p.. jan/mar, 2006.

MOURA, T. A. M. Estudo experimental de superfícies permeáveis para o controle do escoamento superficial em ambientes urbanos. 117p. Dissertação (Mestrado em Tecnologia Ambiental e Recursos Hídricos) - Universidade de Brasília, Brasília, 2005.

OTERPREM BLOCOS E PISOS INTERTRAVADOS DE CONCRETO: Disponível em $<$ http://www.oterprem.com.br/> Acesso em 20/10/2014 